\title{
ALGUMAS NOTAS PARA A LEITURA DE "MANUCURE", DE MÁRIO DE SÁ-CARNEIRO
}

\author{
Ricardo Marques* \\ Universidade Nova de Lisboa
}

Resumo: "Manucure", de Mário de Sá-Carneiro (1890-1916), constitui um dos poemas mais importantes da vanguarda na literatura portuguesa, a par das odes de Fernando Pessoa-Álvaro de Campos e dos poemas-manifesto de Almada Negreiros. O presente artigo pretende não só discutir o longo poema no contexto dessa mesma vanguarda, mas igualmente situá-lo no âmbito da obra de Sá-Carneiro, que foi decididamente influenciada pela amizade, nos últimos quatros anos da sua curta vida, com Fernando Pessoa, de que nos chegou extensa e valiosa correspondência. Desta forma, falaremos não só dos elementos tipográficos do poema, do seu intuito e significado no seio do texto, bem como iremos fazer uma leitura próxima da poética e estilística deste autor, do seu contacto e contaminação com outras vanguardas europeias. Esperamos também demonstrar, com estas notas para a leitura do poema (publicado pela primeira vez no segundo número de Orpheu) a extrema importância das revistas literárias enquanto suporte de criação e difusão dos nomes maiores da literatura portuguesa, especialmente neste primeiro momento do Modernismo português.

Palavras-chave: Modernismo Português. Revistas literárias. Futurismo. Tipografia.

Para Alice Aires, a poeta-manucure

$$
\begin{aligned}
& \text { Grandes cidades paradas nos cafés, } \\
& \text { Nos cafés — oásis de inutilidades ruidosas } \\
& \text { Onde se cristalizam e se precipitam } \\
& \text { Os rumores e os gestos do Útil } \\
& \text { Álvaro de Campos, "Ode Triunfal” }
\end{aligned}
$$

Poema originalmente publicado no segundo número de Orpheu (julho 1915), justamente na ocasião da viagem final de Mário de Sá-Carneiro para Paris (11 julho de 1915), "Manucure" é um texto que se pode considerar absolutamente central na poética deste autor. Para mais, é um poema que simboliza esse encontro essencial do Modernismo português, a amizade entre Fernando Pessoa e Sá-Carneiro, bem como o importantíssimo papel que as

Esta obra está licenciada sob uma Creative Commons - Atribuição 4.0

\footnotetext{
* Ricardo Marques é poeta e desenvolve actividade crítica em revistas da especialidade (Colóquio-Letras, JL, Relâmpago) sendo também tradutor freelance de poesia anglo-saxónica e espanhola. É investigador num pósdoutoramento sobre revistas literárias do Modernismo Português, financiado pela FCT-MCTES (SFRH/BPD/101758/2014). E-mail: <ricardomfm@gmail.com>.
} 
revistas literárias tiveram nesse mesmo contexto.

A verdade é que este segundo número da revista apresenta uma série de modificações formais e de conteúdo que tornam "Manucure" um exemplo ainda mais curioso no seu futurismo (quase) isolado, não obstante as Odes Marítima e Triunfal, de Álvaro de Campos, publicadas no primeiro número de Orpheu. Lembramos, de resto, que Orpheu havia sido a revista do primeiro choque modernista com a sociedade, de que o próprio autor de "Manucure" compila recensões e numerosos artigos num pequeno caderno, agora depositado no espólio do autor, na Biblioteca Nacional de Lisboa.

Efectivamente, este é um poema invulgar, longamente invulgar no seio da poética de Sá-Carneiro, e como tal seria útil nesta leitura começar por decompô-lo em partes. Ana Luísa Amaral, na sua cuidada análise do poema (AMARAL, 2002, p. 105-119), incluída no volume crítico e antológico, denota desde logo a premência de duas partes principais, uma em que o sujeito poético se contém numa estética pós-simbolista que lhe era muito própria, uma maturidade da estética simbolista, e outra, em que se aproxima mais de um poema tipicamente futurista. No entanto, "Manucure" funciona efectivamente como um todo coeso, em que essas duas partes são indissociáveis.

Por último, seria de todo interessante incorporar este poema no campo lexical de SáCarneiro. Se tivermos de selecionar um elemento onde fundear esta poesia, esse elemento seria o Ar, que aparece das mais variadas formas na sua obra poética - seja pela utilização de um campo lexical próximo, seja pelo desdobramento gramatical do mesmo. Efectivamente, é ele que o diz a Pessoa, numa carta de 2 de dezembro de 1912:

Quanto a novas ideias, interessantes têm surgido raríssimas. Falo-lhe apenas duma-
que não sei se já narrei ao meu amigo. É a seguinte: Contar a tragédia do ar, as dores
e as alegrias do ar - o ar como ser, como indivíduo. E falar-se-ia dos comboios
gigantescos que o rompem brutalmente, e das mãos brancas que o acariciam, de
todos os deslocamentos, em suma, que no oceano aéreo se dão. É esta uma ideia
longínqua muito difícil de explicar em poucas palavras. (SÁ-CARNEIRO, 2015, p.
$46-47)^{1}$

Em "Manucure", Ar é a palavra que mais aparece, a par de Beleza, que é outro elemento incontornável neste poeta. Veremos a sua pertinência ao longo desta leitura.

Comecemos assim pelo início, onde nos é dito: "Na sensação de estar polindo as minhas unhas, / Súbita sensação inexplicável de ternura, / Tudo me incluo em Mim piedosamente." O Sensacionismo teorizado, ainda que de forma fragmentária, por Pessoa, e discutida amplamente nas cartas com Mário de Sá-Carneiro, encontra-se aqui poeticamente

\footnotetext{
${ }^{1}$ Carta de 2 de dezembro de 1912. Nesta e em todas as transcrições de cartas neste artigo, usaremos esta edição, que é a mais recente e a mais completa.
} 
realizado. $^{2} \mathrm{O}$ sujeito poético não está efectivamente a polir as unhas, mas projecta-se na sensação de o fazer. Aliás, esta metáfora do verniz, como diz Ana Luísa Amaral é organizadora do poema, aglutinadora das suas variadas partes (AMARAL, 2002, p. 116). O verniz como fachada do exterior da carne é particularmente pertinente num autor como SáCarneiro, em que a tensão eu-outro, via Arthur Rimbaud, encontra uma especial pertinência neste início do Modernismo português. Outros poemas do autor de Dispersão denotam esta mesma metáfora, aliada a esta particular temática.

A seguir a este incipit, Sá-Carneiro, à boa maneira dos poemas modernistas, situa o sujeito poético num café, sentado (vv. 4-8) e é descrito sumariamente o espaço, recorrendo-se aos pressupostos retóricos da hipálage - ou projecção de características de objectos inertes a uma caracterização psicológica, em "bocejos amarelos" - e da sinédoque, descrevendo uma parte do café - as mesas - pela totalidade do espaço: "ingratas/e duras, esquinadas na sua desgraciosidade/ boçal, quadrangular e livre-pensadora."

O verso seguinte, "Fora: dia de Maio em luz", o mais curto de toda a estrofe, funciona semântica e retoricamente como um hiato, e igualmente como ponte, entre o ambiente descrito anteriormente, interior e fechado do café, com o ambiente descrito lá fora (“dia brutal, provinciano e democrático"), um dia que "há-de ter cantores/ Entre os amigos com quem ando às vezes - / trigueiros, naturais de bigodes fartos - que escrevem [...]" num grupo de que não faz parte, já que tal dia soalheiro ofende a sua sensibilidade extrema, a de uns "olhos delicados, refinados, esguios e citadinos." Este trecho é particularmente importante logo a início pela forma antitética com que são dispostos os elementos introdutórios do poema: eu vs os outros, numa equação que se poderia resumir a uma predisposição dionisíaca e citadina por oposição a uma de tom mais apolíneo e campestre.

A "sensação de polir as unhas" ganha assim uma nova pertinência quando reafirmada novamente no primeiro verso da estrofe seguinte (v. 21), que deixa de lado os elementos concretos da primeira estância, para descolar em voos de gosto simbolista (a estética do subtil e do vago, palavra aliás usada nesta estrofe) servida pela utilização frequente dos adjectivos (e frequentemente tripla, e por isso bastante enfática). Aliás, se aqui já não houvesse mais dúvidas da localização do poema, Sá-Carneiro utiliza o adjectivo toponímico "parisiense"

\footnotetext{
${ }^{2}$ O Sensacionismo é o último ismo criado por Fernando Pessoa, c. 1915, vindo este no afã de outros dois Paulismo e Interseccionismo - criado nos anos imediatamente anteriores (c. 1913-14, 1914-15, respectivamente), e vindo funcionar como ismo aglutinador de todos eles. De forma a podermos dizer que, ainda que estejamos perante um poema sensacionista, a sua filiação estética e técnica tenha mais directamente a ver com o Interseccionismo - um dos seus elementos - como veremos adiante. Para esta questão, recomenda-se a leitura de Pessoa (2009), bem como Cabral Martins (2015, p. 97-106).
}

Anu. Lit., Florianópolis, v. 21, n. 2, p. 30-41, 2016. ISSNe 2175-7917 
para caracterizar esse tal verniz com que se mascara e se isola do mundo à sua volta. Trata-se efectivamente de uma pose despersonalizada, citadina e modernista, de um Sá-Carneiro que podemos igualmente ler em "Caranguejola" ou aflorada em "Crise Lamentável” ("Não andar por Paris, como ando às moscas"), entre inúmeros outros exemplos. ${ }^{3}$

Por outro lado, toda esta questão metafórica do verniz como força de tensão entre eumim retornará de forma menos subtil num dos últimos poemas, datado de fevereiro de 1916, mais uma vez chegado até nós porque endereçado por carta a Fernando Pessoa, e que se intitula, muito claramente, "Feminina". Neste poema, o sujeito poético declara repetidamente, numa anáfora em cada início de estrofe, que "Eu queria ser mulher", condição que lhe serviria uma série de propósitos, e que são resumidos no seguinte trecho-clímax: "Eu queria ser mulher para excitar quem me olhasse, / Eu queria ser mulher pra me poder recusar.... [ [...] Ah, que te esquecesses sempre das horas/polindo as unhas - / A impaciente das morbidezas louras/Enquanto ao espelho te compunhas." Se no poema "Manucure" a tal tensão despersonalizante vive de uma tentação de género, com um sujeito poético fazendo uma "manucure" metafórica e feminina, aqui a subtileza é obliterada muito provavelmente pelo pressentimento da proximidade do fim, num poema "irritantíssimo", tal como o descreve a Pessoa. ${ }^{4}$

Creio que é igualmente importante relembrar aqui a situação editorial deste poema, isto é, a sua posição tal qual foi impresso pela primeira vez, no primeiro número de Orpheu. "Manucure" encontrava-se precedido de um outro poema, "Elegia", constituindo estes um grupo intitulado curiosamente "Poemas sem suporte". Uma breve análise de "Elegia" revela o autor pós-simbolista que conhecemos de outros poemas, mostrando o seu domínio da quadra sinestésica, e de muitas formas este poema é uma introdução contida ao grande poema "semifuturista" (tal como Fernando Pessoa o caracterizou) que é "Manucure". Este poema é uma verdadeira elegia para si próprio, para um tempo inexorável que o faz afundar no abismo da sua auto-reflexão - "Meus boulevards de Europa e beijos/Onde fui só um espectador... / Que sono lasso, o meu amor; / Que poeira de ouro, os meus desejos". Mais uma vez, a estrofe final de "Elegia" não só atinge a apoteose deste sentimento de auto-desconhecimento e de despersonalização, como igualmente parece introduzir a situação geográfico-espacial do início de "Manucure”: "Ó meus cafés de grande-vida / Com dançarinas multicolores... / - Ai,

\footnotetext{
${ }^{3}$ Recomendamos a leitura do artigo de Ricardo Vasconcelos (2013), "Painting the Nails with a Parisian Polish Modern Dissemination and Central Redemption in the Poetry of Mário de Sá-Carneiro" onde o especialista analisa de que forma a cidade de Paris contribui para a definição de uma identidade moderna fragmentada na poesia de Mário de Sá-Carneiro.

${ }^{4}$ A referida carta é de 16 de fevereiro de 1916 (cf. SÁ-CARNEIRO, 2015, p. 469-472).
} 
não são mais as minhas dores / Que a sua dança interrompida..."

\title{
"Sentir tudo de todas as maneiras"
}

Tal como defende Paula Cristina Costa, é em Mário de Sá-Carneiro que o Interseccionismo mais se faz sentir, nomeadamente com "Manucure",

\begin{abstract}
[...] poema que ao exaltar toda uma estética cubista e futurista, utiliza a sucessiva e vertiginosa interpenetração de planos, a mistura de sensações e de registos diferentes, que vão desde a situação inicial da vivência de café deste poeta (muito ao gosto dos poetas de Orpheu) que lima o seu tédio enquanto vai polindo as suas unhas, até às encenações as ousadas e hilariantes da aventura de uma nova beleza que, em mutações apoteóticas canta a liberdade das palavras e da imaginação." (COSTA, 2008, p. 364)
\end{abstract}

Passado que foi a introdução do espaço-tempo deste poema, já aflorado atrás, a presença do interseccionismo é claro quando diz, de forma resumida, nas últimas linhas desta parte: "E tudo, tudo assim me é conduzido no espaço / Por inúmeras intersecções de planos / Múltiplos, livres, resvalantes.” (vv. 39-41). Repare-se na tripla adjectivação, característica do autor, mas igualmente nas diversas tonalidades de cada um dos adjectivos, eles próprios “interseccionistas" uma vez que caracterizam esses "planos" de forma sinonímica e poliédrica, lembrando aliás a estética cubista e expressionista do período. A quadra seguinte é igualmente apanágio desta confluência interseccionada de planos onde o sujeito poético se encontra, sem qualquer tempo que não seja o do próprio texto, já aflorada, como se viu, em "Elegia": "É lá, no grande Espelho de fantasmas / Que ondula e se entregolfa todo o meu passado, / Se desmorona o meu presente, / E o meu futuro é já poeira" (vv. 42-45).

Após uma linha cheia de pontos, recorrente em Sá-Carneiro (a par do uso abundante das reticências) e que parece indicar a passagem a um outro momento do poema, o sujeito poético depõe "então as minhas limas, / As minhas tesouras, os meus godets de verniz, / Os polidores da minha sensação - / E solto meus olhos a enlouquecerem de Ar”. Como se pode ler, o registo muda, e agora é no ar, que aqui lemos como a atmosfera, onde tudo existe à volta, que o sujeito se fixa. O desejo íntimo do sujeito é então enunciado pela primeira vez, naquilo que o poema nos duzentos versos seguintes fará - “Oh, poder exaurir tudo quando nele [Ar] se incrusta, / Varar a sua Beleza - sem suporte, enfim! -”. Repare-se na dupla grafia maiusculada das suas palavras - Ar e Beleza, como dizíamos atrás. A esta ânsia-desígnio do próprio poema sucede então uma grande enumeração anafórica (“Que...") de tudo o que existe no ar (vv. 55-60). Localizando-se agora "pelas estações e cais de embarque", onde “Tudo [está] inserto no Ar" (v. 70), o sujeito profere, já em pleno sentimento futurista, “- Ó beleza futurista das mercadorias!", antes de entrar numa extensa exemplificação de ideias, a 
que imiscui o primeiro trecho tipográfico do poema:

\title{
FRAGIL！FRAGIL!
}

\author{
$843-A G$ LISBON
}

\section{$492-$ WR MADRID}

\section{TIPOGRAFIA:}

\author{
Sereno. \\ Em minha face assenta-se um estrangeiro \\ Que desdobra o "Matin". \\ Meus olhos, já tranquilos de espaço, \\ Ei-los que, ao entrever de longe os caracteres, \\ Começam a vibrar \\ Toda a nova sensibilidade tipográfica. (negritos nossos) (vv. 170-176)
}

Dizíamos a início que este é um poema onde se denota um futurismo (quase) isolado, mercê da pouca proliferação do movimento em Portugal. Numa comparação que das maiúsculas faz Patrícia da Silva MacNeill, no seu artigo incluído no livro celebratório dos 100 anos de Orpheu, 1915: O Ano de Orpheu, em que se coteja a revista portuguesa com Blast ${ }^{5}$, é aflorado pela primeira vez esta pertinente proximidade estética entre as duas publicações:

\begin{abstract}
Efectivamente, o título em letras maiúsculas e o número que aparecem na capa da revista portuguesa assemelham-se ao título em maiúsculas garrafais da capa do primeiro número da Blast e aos números destacados em negrito do primeiro manifesto vorticista. // As maiúsculas reaparecem no poema "Manucure", de SáCarneiro, que apresenta uma variedade de tipos e tamanhos que provavelmente ocasionaram o comentário congratulatório deste às escolhas editoriais de Pessoa. (MACNEILL, 2015, p. 172)
\end{abstract}

A brincadeira com a mancha gráfica na página aparece, no entanto, na supracitada correspondência de Sá-Carneiro por duas vezes, nomeadamente nos postais de novembro e dezembro de 1914, de que reproduziremos um exemplo em baixo. Esta influência é certamente devida à estadia parisiense, onde conhece as invectivas cubistas e futuristas, e onde priva directamente com figuras ilustres, já neste período, como é o caso de Guillaume

\footnotetext{
${ }^{5}$ Blast é o nome de uma revista modernista inglesa, de que saíram dois números - um em junho de 1914 e outro um ano depois - e que canalizou os ideais do movimento vorticista. Os seus principais protagonistas foram Ezra Pound e Wyndham Lewis. Fernando Pessoa possuía o primeiro número na sua biblioteca pessoal.
} 
Apollinaire (1882-1918). Como se vê numa das cartas, de 18 de novembro de 1914, talvez a mais conhecida de entre as duas referidas, Sá-Carneiro quase aplica o princípio caligramático inventado pelo poeta e soldado francês:

Carta de Mário de Sá-Carneiro para Fernando Pessoa (18 nov. 1914)

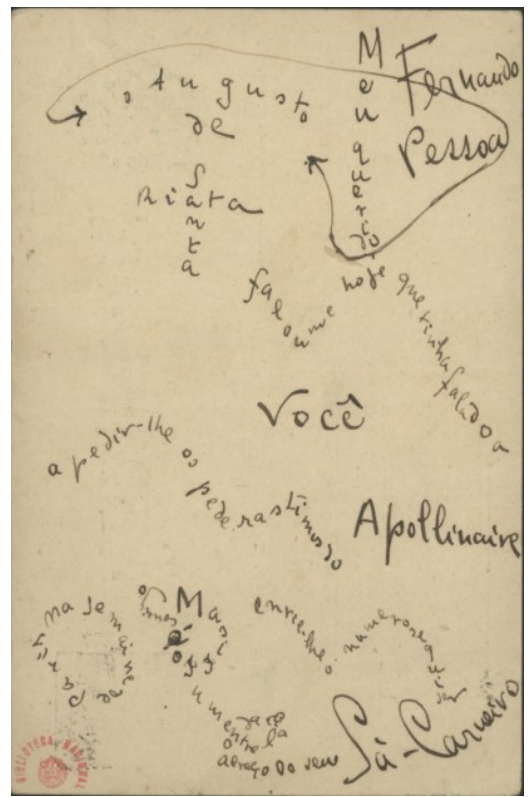

Fonte: Biblioteca Nacional de Lisboa (SÁ-CARNEIRO, 2015, p. 294)

Meu querido Fernando Pessoa

O Augusto de Santa-Rita falou-me hoje que tinha falado a Você a pedir-lhe os pederestismos do Apollinaire na Semaine de Paris. Mas isso é consigo envie-lhe o número se quiser um entrelaçado abraço do seu

Sá-Carneiro ${ }^{6}$

Ora, os caracteres tipográficos incluídos em "Manucure" derivam de um gosto pela experimentação a la Apollinaire, mas certamente a intenção de ser uma blague, querendo directamente atingir os futuristas, é aqui prevalente. Aliás, na célebre carta de 30 de junho de 1914, onde é largamente comentada a "Ode Triunfal”, Sá-Carneiro diz que "Do que até hoje eu conheço futurista - a sua ode não é só a maior - é a única coisa admirável”, o que, marcadamente exagerada ou não, revela que o seu gosto pessoal não se coadunava com leituras dos futuristas. Aliás, quando volta a Paris pela última vez, é visível uma certa atitude desdenhosa de Sá-Carneiro (quem sabe partilhada íntima e epistolarmente por Fernando Pessoa) na carta que a este envia a 13 de agosto de 1915, depois de uma visita à Galeria de um negociante de quadros futuristas, Sagod:

\footnotetext{
${ }^{6}$ Transcrição da nossa responsabilidade, da carta-postal de 18 de Novembro de 1914. (SÁ-CARNEIRO, 2015, p. 293-294).
} 
$\mathrm{Na}$ galeria Sagod, o templo cubista futurista de que lhe falei já numa das minhas cartas comprei ontem um volume: I Poeti Futuristi. É uma antologia abrangendo o Marinetti e muitos outros poetas: Mário Bétuda, Libero Altomare, etc, etc. Em acabando de ler o catrapázio (1 semana) vou-lho mandar em presente. Já lá descobri uns $\mathrm{Fu}$ fu... cri-cri... corcurucu... Is-holá..., etc. muito recomendáveis. Vamos ver... [...] (SÁ-CARNEIRO, 2015, p. 351).

A atitude, como se vê, varia entre o desprezo lúdico e a admiração estética, como se o Futurismo fosse uma escola estranha a si próprio. Por outro lado, a penúltima imagem tipográfica de "Manucure" é bem reveladora do seu conhecimento da Paris artística e literária de então, a que não se limita a comparar ao caso português, numa equação que lembra a do colega futurista Álvaro de Campos (“O binómio de Newton é tão belo como a Vénus de Milo."):

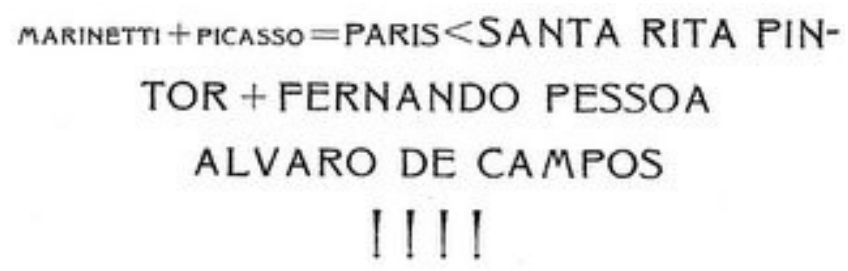

Apesar de blague, Mário de Sá-Carneiro revela conhecer o seu objecto de paródia literária, o que alimenta ainda mais esta duplicidade entre a ridiculização do reductio ad absurdum dos princípios literários futuristas, e a sua mesma aplicação experimental de forma empenhada e cuidada, tornando-a uma criação muito sua. ${ }^{7}$

O momento final do poema (vv. 218-235), precedendo a última colagem tipográfica, de que falaremos adiante, parece indicar um deslindar desta situação do café - o sujeito poético acaba a sua descrição à velocidade futurista de tudo o que existe no ar (numa das outras colagens tipográficas, esta roçando o conceito de poema visual, diz-nos "É no ar que ondeia tudo! É lá que tudo existe!...”) e levanta-se concluindo que tudo o que acaba de narrar, em ideal de beleza "pura", é "inatingível” - "nunca em meus versos poderei cantar" (v. 225), restando apenas sair em corrida "para a rua aos pinotes e aos gritos", uma vez mais seguindo

\footnotetext{
${ }^{7}$ Curiosamente, a própria impressão póstuma foi alvo de um grande erro tipográfico, mercê de uma confusão que se generalizou, logo patente no volume Poesias (1946), da série de obras completas que a Ática publicou, e que constituiu a sua primeira reedição, três décadas exactas depois da morte do autor. Tal erro patenteia-se pela separação artificial que é feita sensivelmente a meio do poema (vv. 123-124), na palavra "APOTEOSE", impressa tipograficamente. Esta é seguida de uma linha de pontos, seguindo a estilística, aliás, de Mário de SáCarneiro não só para este poema como para outros. A confusão tipográfica dever-se-á explicar não só por esta separação gráfica que o próprio autor faz, mas pelo facto de a continuação do poema mostrar uma explosão a nível de ritmo e de significado que não terá tanto a ver com o que o precede, quando na verdade apenas a continua. Por outro lado, a própria palavra "Apoteose" - título, de resto, de outro poema de Sá-Carneiro - é um sinal dúbio quanto à conclusão, ou não, do próprio poema. O erro encontra-se colmatado desde a edição crítica de Fernando Cabral Martins: Poemas Completos, Lisboa, Assírio e Alvim, 1996.
}

Anu. Lit., Florianópolis, v. 21, n. 2, p. 30-41, 2016. ISSNe 2175-7917 
uma satirização do estereótipo do poeta futurista.

\section{"Éramos como um diálogo numa alma" 8}

A "Ode Triunfal" do heterónimo futurista Álvaro de Campos e "Manucure" de Mário de Sá-Carneiro, parecem ser, assim, dois vértices de uma mesma vanguarda futurista, dois poemas que exprimem, no primeiro modernismo português, o melhor que a vanguarda produziu na literatura portuguesa.

Ainda que o tempo de escrita os separe sensivelmente um ano - "Ode Triunfal" é escrita em junho de 1914, enquanto que "Manucure" data de maio de 1915 - o tempo da sua publicação aproxima-se de forma coerente - o poema de Campos é publicado no primeiro número de Orpheu, enquanto que o poema de Sá-Carneiro sai no número seguinte - tendo os respectivos poemas sido lidos, antes da sua publicação, pelos dois amigos. É interessante repescar justamente o que da "Ode Triunfal" diz Sá-Carneiro, numa carta de 30 de junho de 1914, escrita a Pessoa:

Não tenho dúvida em assegurá-lo, meu Amigo, você acaba de escrever a obra-prima do Futurismo. Porque apesar talvez de não pura, escolarmente futurista, o conjunto da ode é absolutamente futurista. [...] Depois de escrita a sua ode, meu querido Fernando Pessoa, eu creio que nada mais de novo se pode escrever para cantar a nossa época. (SÁ-CARNEIRO, 2015, p. 223)

Existe então uma proximidade entre os dois poemas que não passa apenas pela temática, como igualmente pela intersecção de planos, e elementos enfáticos empregues (como as interjeições - "Eia", por exemplo).

Há, em primeiro lugar, um fingimento de lugar que em tudo tem a ver com a própria estética pessoana. O engenheiro Álvaro de Campos afirma, através dos elementos pós-textuais do fim do poema, que este havia sido escrito em Londres - o que sabemos biograficamente ser impossível - mostrando um espaço nitidamente anglófono, pela referência de nomes, profissões e transportes (um pouco como em The Wasteland, de T. S. Eliot, na década seguinte, contemporâneo da Semana da Arte Moderna no Brasil, em 1922). Já Sá-Carneiro remete a situação geográfico-espacial do seu poema para um outro pólo urbano importante para o Modernismo - Paris, cidade que efectivamente conheceu e onde viria a morrer, a 26 de abril de 1916, mas onde igualmente não se encontra no momento da sua escrita. É que, lembremos, a vanguarda é a arte das cidades, como Marinetti deixou bem expresso nos seus manifestos - mesmo que "a melhor maneira de viajar seja sentir", como escreveu e viveu

\footnotetext{
${ }^{8}$ Verso do poema "Sá-Carneiro", de Fernando Pessoa, datado de 1934.
} 
Pessoa. E, como confessa noutra carta de Paris, após dizer compreender que Pessoa vive num exílio auto-imposto em Lisboa, tentando "sentir tudo de todas as maneiras", saindo de si e andando pelo mundo: "Oiça: Eu amo incomparavelmente mais Paris, eu vejo-o bem mais nitidamente e compreendo-o em bem maior lucidez longe dele, por Lisboa, do que aqui, nos seus boulevards [...]" (SÁ-CARNEIRO, 2015, p. 236).

\section{"Outra maravilha o final com as suas onomatopeias"9}

A conclusão é então uma homenagem-colagem final, tanto a Marinetti, quanto a Campos, seu compagnon de route. Inspirado, provavelmente, na ode do colega futurista, conclui Sá-Carneiro o seu poema com um chorrilho de onomatopeias, em verdadeira performance futurista por parte do sujeito poético, que assim sai para a rua e do poema: "Hilá! Hilá! Hilá-hô! Eh! Eh!...” (v. 236). De seguida, inclui o autor uma citação indirecta ao poema "Zang Tumb Tumb" de Marinetti, evocando sons repetitivos de máquinas, de palavras em liberdade (parole in libertà) sem qualquer significação adicional aparente. ${ }^{10}$

PLIIIHIIIII. . .

BRÁ-ÔH ... BRÁ-0̂H ... BRÁ-0̂H $\ldots \ldots$

PUTSCH! FOTSCH !...

ZING-TANG... ZNMG-TANG ...

TANG... TANG... TANG..

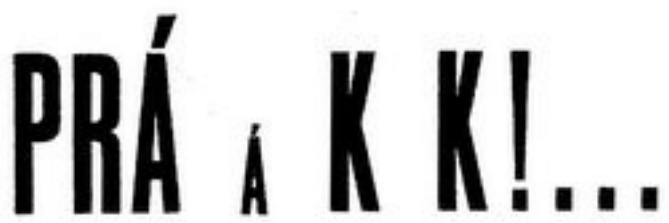

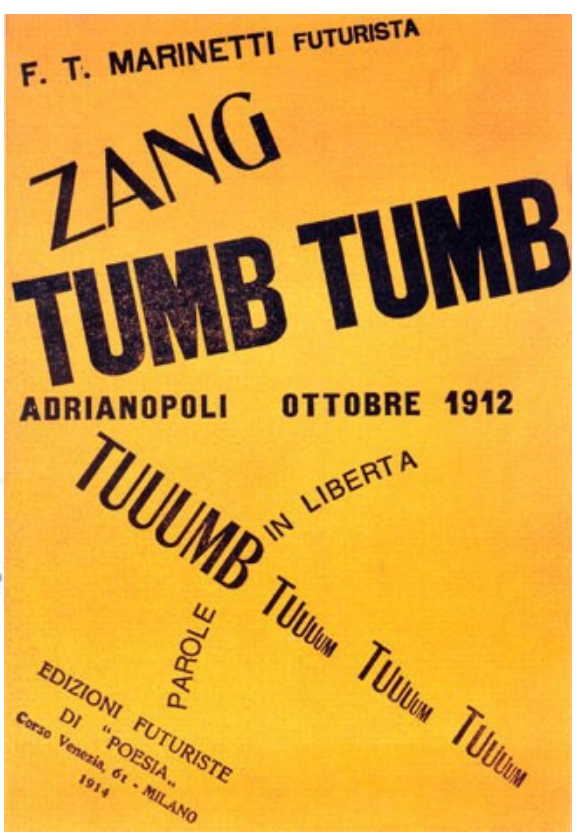

Verdadeiro poema interseccionista, pensamos ter demonstrado como "Manucure"

\footnotetext{
${ }^{9}$ Carta de Sá-Carneiro de 30 de Junho de 1914, referindo-se a "Ode triunfal”. Cf. SÁ-CARNEIRO, 2015, p. 224.

${ }^{10}$ Ainda assim há quem veja nestas onomatopeias algum significado. É o caso de Ana Luísa Amaral: "E, se as onomatopeias com que o poema fecha [...] evocam o "Zang Tumb Tuum", de Marinetti, a onomatopeia final "Prá Á Kk", seguida da exclamação e reticências, evoca, na sequência, o som de um elástico que se parte, ou de um chicote a estalar [...] ou, mais imaginativamente, o som do verniz que estala e se fragmenta." (AMARAL, 2002, p. 119).
} 
parece ser um poema levado a um extremo futurista, por meio de uma blague que se tornou literatura séria, inspirada por um diálogo estético profundo e profícuo com Fernando Pessoa.

\section{Referências}

AMARAL, Ana Luísa, Manucure. In: SILVESTRE, Osvaldo Manuel; SERRA, Pedro. (Orgs.). Um Século de Ouro: Antologia Crítica da Poesia Portuguesa do Século XX. Coimbra: Angelus Novus, 2002, p. 105-119.

CABRAL MARTINS, Fernando. Introdução ao Estudo de Fernando Pessoa. Lisboa: Assírio e Alvim, 2015.

COSTA, Paula Cristina. Interseccionismo. In: MARTINS, Fernando Cabral. Dicionário de Fernando Pessoa e do modernismo português. Lisboa: Caminho, 2008, p. 363-366.

MACNEILL, Patrícia. Orpheu e Blast: Interseções do Modernismo Português e Inglês. In: DIX, Steffen (Org.). 1915 - O Ano do Orpheu . Lisboa: Tinta da China, 2015, p. 167-183.

PESSOA, Fernando. Sensacionismo e outros ismos. Edição crítica de Jerónimo Pizarro. Lisboa: INCM, 2009.

SÁ-CARNEIRO, Mário de. Em Ouro e Alma - Correspondência com Fernando Pessoa. Edição Jerónimo Pizarro e Ricardo Vasconcelos. Lisboa: Tinta da China, 2015. 2005.

Poemas Completos. Edição Fernando Cabral Martins. 3. ed. Lisboa: Assírio e Alvim,

VASCONCELOS, Ricardo, Painting the Nails with a Parisian Polish Modern Dissemination and Central Redemption in the Poetry of Mário de Sá-Carneiro. Pessoa Plural, n. 4, 2013. Disponível em: https://www.brown.edu/Departments/Portuguese_Brazilian_Studies/ejph/pessoaplural/issues. html>. Acesso em: 7 jul. de 2016.

\section{Créditos das imagens}

Carta de Mário de Sá-Carneiro para Fernando Pessoa (18 Nov. 1914). Fonte: Biblioteca Nacional de Lisboa (Reproduzida em SÁ-CARNEIRO, 2015, p. 294)

[Recebido em 26 de julho de 2016 e aceito para publicação em 28 de julho de 2016]

\section{Some notes towards the reading of "Manucure" by Mário de Sá-Carneiro}

Abstract: "Manucure", by Mário de Sá-Carneiro (1890-1916), is one of the most important vanguardist poems of in Portuguese literature, alongside with the Fernando Pessoa-Álvaro de Campos' odes and the manifest-poems by Almada Negreiros. This article aims at not only discuss this long poem in the context of that vanguard, but also to place it in Sá-Carneiro's oeuvre, which was decisively influenced by the friendship, in the last four years of his short life, with Fernando Pessoa, of what an extensive and valuable correspondence is proof of. Therefore, we'll not only speak about the typographic elements of the poem, its purpose and meaning in the text, we will also do a close reading of the poetic and stylistic aspects of this author, his contact and contamination with other European vanguards. We also hope to 
demonstrate with these notes towards the reading of the poem (firstly published in the second issue of Orpheu) the extreme importance of literary magazines while creative support and source of dissemination of the biggest names of our literature, especially at this early moment of Portuguese Modernism.

Keywords: Portuguese Modernism. Literary Magazines. Futurism. Tipography.

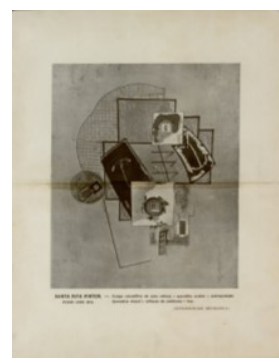

